CARDIOVASCULAR MEDICINE

\title{
Predictors of adverse outcome in patients with arrhythmogenic right ventricular dysplasia/ cardiomyopathy: long term experience of a tertiary care centre
}

\author{
K Lemola, C Brunckhorst, U Helfenstein, E Oechslin, R Jenni, F Duru
}

Heart 2005;91:1 167-1172. doi: 10.1136/hrt.2004.038620

See end of article for authors' affiliations .....................

Correspondence to: Dr Firat Duru,

Cardiovascular Centre, University Hospital of Zurich, Rämistrasse 100 $\mathrm{CH}-8091$, Zurich, Switzerland; firat.duru@ dim.usz.ch

Accepted 15 July 2004

\begin{abstract}
Objective: To investigate the predictors for adverse clinical outcome in patients with arrhythmogenic right ventricular dysplasia/cardiomyopathy (ARVD/C) during long term follow up.

Methods: 61 patients with ARVD/C were studied to assess the impact of family history, clinical findings, surface ECG parameters, echocardiographic findings, and electrophysiological findings on clinical outcome. The prevalence of these risk factors were compared in two patient groups: group A (patients with adverse clinical outcome: sudden cardiac death, death from heart failure, or heart transplant) and group $B$ (survivors excluding patients who received a heart transplant).

Results: Mean age at first diagnosis was 44 (14) years. The mean follow up duration was 55 (47) months. Ten patients $(16 \%)$ died during follow up. The cause of death of eight of these patients was probably arrhythmic. Two patients died of advanced heart failure. Five patients underwent heart transplantation because of terminal heart failure. Risk factors significantly associated with adverse outcome were history of congestive heart failure $(p<0.001)$, the presence of left ventricular involvement on echocardiography $(p<0.001)$, left atrial dilatation $(p<0.05)$, prolonged PR duration $(p<0.01)$, prolonged $Q R S$ in V1 $(p<0.05)$, and bundle branch block $(p<0.05)$. In multivariate analysis, history of congestive heart failure and presence of left ventricular involvement were identified as independent risk predictors for an adverse outcome.

Conclusions: Congestive heart failure and left ventricular involvement are independently associated with adverse outcome in patients with ARVD/C during long term follow up.
\end{abstract}

A rrhythmogenic right ventricular dysplasia/cardiomyopathy $(\mathrm{ARVD} / \mathrm{C})$ is a genetically determined heart disease characterised by progressive fibrofatty replacement of the right ventricular myocardium. The disease is a major cause of sudden cardiac death in young adults and athletes. ${ }^{1-7}$ The clinical course of ARVD/C may be considerably variable. Cardiac electrical instability in ARVD/C may be associated with ventricular arrhythmias. Ventricular tachycardia and fibrillation are well documented causes of sudden death in ARVD/C. ${ }^{6-8}$ Non-sudden cardiac death in ARVD/C may result from progressive right or biventricular involvement leading to terminal heart failure. ${ }^{9-11}$ The purpose of this study was to identify the clinical, ECG, echocardiographic, and electrophysiological predictors of long term outcome in patients with ARVD/C.

\section{METHODS}

\section{Study population}

ARVD/C was diagnosed in 61 patients (mean age 44 (14) years; 44 men, 17 women) at our institution based on standardised diagnostic criteria. ${ }^{12}$ Presence of other heart diseases, such as coronary artery disease or dilative cardiomyopathy, was excluded in all patients. The analysed parameters were clinical and family history, surface ECG parameters, and echocardiographic and electrophysiological findings.

At presentation, 45 patients had ventricular tachycardia. Eleven patients had syncope as the presenting symptom, 15 patients had presyncope, six patients had symptoms and signs of congestive heart failure, and 20 patients had palpitations. Three patients were asymptomatic but had a positive family history for ARVD/C or sudden cardiac death, and $A R V D / C$ was diagnosed in one patient during a routine check up.

\section{Analysis of clinical outcome}

The impact of family history, clinical findings, surface ECG parameters, and echocardiographic and electrophysiological findings on clinical outcome were investigated in all patients. The prevalence of these risk factors was compared in two outcome groups: group A (patients with adverse outcome: sudden cardiac death, death from heart failure, and heart transplant) and group B (survivors and those who did not require heart transplantation).

\section{Surface ECG}

ECG analysis focused on the presence of epsilon waves, $\mathrm{T}$ wave negativity in precordial leads beyond Vl, the presence of bundle branch block, and the duration of PR, QRS, and QT intervals. ${ }^{13}{ }^{14}$ None of the patients had a Brugada-like ECG pattern during follow up, characterised by high take-off ST segment elevation $\geqslant 1 \mathrm{~mm}$ of "coved" or "saddle back" type. ${ }^{15}$ The PR interval was measured from the beginning of the $\mathrm{P}$ wave to the beginning of the $\mathrm{Q}$ wave. The duration of the QRS complex was measured in leads VI and V6 from the beginning of the QRS complex to its end. When the offset of the QRS complex was difficult to determine due to a gradual

Abbreviations: ARVD/C, arrhythmogenic right ventricular dysplasia/ cardiomyopathy; ICD, implantable cardioverter-defibrillator 
Table 1 Population characteristics of 61 patients

\begin{tabular}{lllll}
\hline & & & \multicolumn{2}{l}{ Comparison at time of diagnosis } \\
\cline { 5 - 5 } & No. & $\begin{array}{l}\text { Survival analysis } \\
\text { (log rank } \mathbf{p})\end{array}$ & $\begin{array}{l}\text { Group A (adverse } \\
\text { outcome) }(\mathbf{n}=15)\end{array}$ & $\begin{array}{l}\text { Group B (survivors) } \\
\text { (n= 46) }\end{array}$ \\
\hline Women & 17 & 0.227 & 5 & 12 \\
Men & 44 & & 10 & 34 \\
Family history of ARVD/C & 10 & 0.206 & 5 & 5 \\
Age at diagnosis (years) & 61 & 0.723 & $42(15)$ & $38(13)$ \\
\hline
\end{tabular}

slope towards a plateau, it was measured at the intersection of the $\mathrm{S}$ wave with the isoelectric baseline. The QT interval was taken in leads in Vl and V6 from the onset of the QRS complex to the end of the T wave. QTc was calculated according to the Bazett formula. ${ }^{16}$ The QT interval was not measured for patients with a bundle branch block.

\section{Transthoracic echocardiography}

Transthoracic echocardiograms were recorded in a standard fashion in two dimensional and Doppler echocardiography and $\mathrm{M}$ mode measurements. ${ }^{17-19}$ Left ventricular ejection fraction was calculated with the biplane area-length method. ${ }^{20}$ Right ventricular morphology was evaluated from multiple views. All measurements were obtained from the apical four chamber view: end systolic right atrial long axis (normal $<5.0 \mathrm{~cm}$ ) and short axis (normal $<4.1 \mathrm{~cm}$ ); right ventricular end diastolic short axis diameter in the middle third of the right ventricle; and right ventricular end diastolic (area D) and end systolic areas (area S). The fractional area change (normal $>25 \%$ ) of the right ventricle was defined as the ratio between the difference of the end diastolic and end systolic right ventricular areas and the end diastolic area (that is, fractional area change $=[$ area $\mathrm{D}-$ area $\mathrm{S}] /$ area $\mathrm{D}$ ). The measurements were corrected for body surface area. The right ventricular wall segments were classified as hypokinetic, akinetic, or dyskinetic. Aneurysms (dyskinetic areas in systole) and localised wall thinning of the ventricular walls were identified. Left ventricular involvement of the disease was considered to be present either in the presence of reduced ejection fraction $(\leqslant 50 \%)$, if other causes were excluded, or in the presence of localised left ventricular dysplastic areas (aneurysms and localised wall thinning).

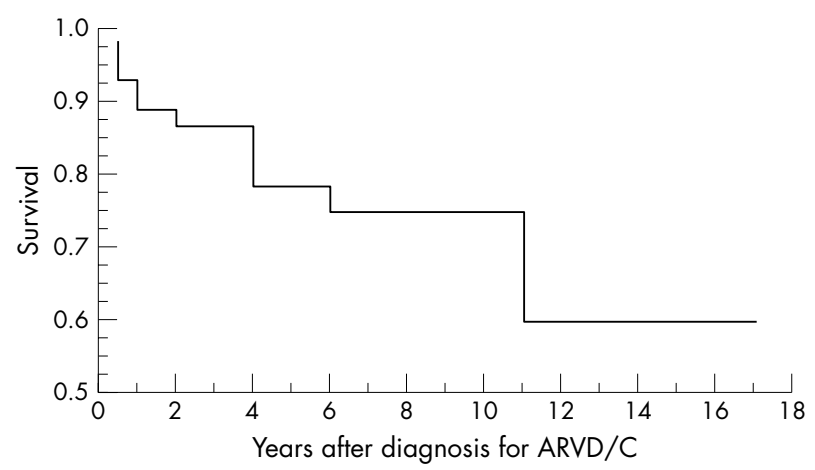

\begin{tabular}{|l|l|l|l|l|l|l|l|l|l|l|l|l|l|l|l|l|l|l|l|}
\hline FU year & 0 & 1 & 2 & 3 & 4 & 5 & 6 & 7 & 8 & 9 & 10 & 11 & 12 & 13 & 14 & 15 & 16 & 17 & 18 \\
\hline Paiens & 57 & 6 & 39 & 33 & 3 & 26 & 22 & 17 & 1 & 7 & 7 & 5 & 2 & 2 & 2 & 2 & 2 & 1 & 0 \\
\hline
\end{tabular}

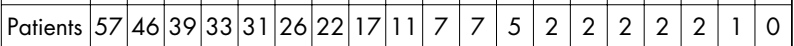

Figure 1 Kaplan-Meier survival analysis (cumulative proportion surviving) of 57 patients with diagnosed arrhythmogenic right ventricular dysplasia/cardiomyopathy (ARVD/C) (time from correct diagnosis to cardiac death or heart transplantation). The numbers of patients remaining at risk for death or heart transplantation during follow up (FU) are listed beneath the plot.

\section{Invasive diagnostic procedures}

A standardised electrophysiological study was performed in 41 patients in the absence of antiarrhythmic drugs, including the delivery of up to three extrastimuli at three basic cycle lengths and ventricular burst pacing at two right ventricular sites (right ventricular apex and outflow tract). Sustained ventricular tachycardia was defined as tachycardia of ventricular origin with a duration longer than 30 seconds or that leading to haemodynamic compromise.

In 29 patients, a right ventricular contrast angiogram was recorded by a standard approach with left anterior oblique and right anterior oblique projections..$^{21} 22$ End diastolic volumes were measured by the surface length method: the long axis of the right ventricle was measured in diastole between the superior border of the tricuspid annulus and the ventricular apex. Other parameters investigated were right ventricular ejection fraction, presence or absence of deep fissures, and localised akinetic or dyskinetic bulges and outpouchings. Magnetic resonance imaging was performed in occasional cases to visualise the extent of the fatty infiltration. ${ }^{23}$

\section{Statistical analysis}

All data were analysed with Statistica (version 6.0; StatSoft, Inc, Tulsa, Oklahoma, USA). The Kaplan-Meier product limit method was used to describe clinical outcome. The time of diagnosis for ARVD/C was considered to be the starting point for this analysis. The end points were death or heart transplantation. The survival plots were compared by the log rank test. ${ }^{24}$ Only significant parameters in univariate survival analysis were considered for multivariate testing. A forward variable selection (Cox proportional hazards) model determined independent variables with effect on time to death or heart transplantation. ${ }^{25}$ The multivariate analysis was limited to those variables that were complete and had no missing data.

\section{RESULTS}

The mean follow up period was 55 (47) months. Table 1 summarises the demographic data of the study population. Ten patients died during follow up. The annual rate of death was $4 \%$. The cause of death of eight of these patients was probably arrhythmic (sudden cardiac death). Two patients died of advanced heart failure. Five of the 61 patients underwent successful heart transplantation because of terminal heart failure.

Figure 1 shows the clinical outcome analysis of the entire ARVD/C population. This analysis defines death or heart transplantation as survival end point for each patient. Age at diagnosis, sex, and family history of ARVD/C were not significant predictors for adverse clinical outcome. Table 2 lists symptoms and signs at time of diagnosis of ARVD/C and their prevalence in the two patient groups. Presence of signs and symptoms of congestive heart failure was found to be significantly associated with adverse outcome. On the surface ECG, prolonged PR interval, prolonged QRS duration in Vl, and the presence of bundle branch block (13 patients: 11 
Table 2 Symptoms and signs in 61 patients with arrhythmogenic right ventricular dysplasia/cardiomyopathy (ARVD/C) at time of diagnosis

\begin{tabular}{|c|c|c|c|c|}
\hline & \multirow[b]{2}{*}{ No. } & \multirow[b]{2}{*}{$\begin{array}{l}\text { Survival analysis } \\
\text { (log rank p) }\end{array}$} & \multicolumn{2}{|c|}{$\begin{array}{l}\text { Comparison at time of } \\
\text { diagnosis }\end{array}$} \\
\hline & & & $\begin{array}{l}\text { Group A } \\
(n=15)\end{array}$ & $\begin{array}{l}\text { Group B } \\
(n=46)\end{array}$ \\
\hline Aborted SCD & $8(13 \%)$ & 0.565 & $3(20 \%)$ & $5(11 \%)$ \\
\hline Aborted SCD or syncope & $27(44 \%)$ & 0.938 & $6(40 \%)$ & $21(46 \%)$ \\
\hline Aborted SCD, syncope, or presyncope & $42(69 \%)$ & 0.334 & $8(53 \%)$ & $34(74 \%)$ \\
\hline Congestive heart failure & $7(11 \%)$ & $<0.0001^{*}$ & $6(40 \%)$ & $1(2 \%)$ \\
\hline VT & $46(75 \%)$ & 0.856 & $10(67 \%)$ & $36(78 \%)$ \\
\hline VT with $L B B B$ & $44(72 \%)$ & 0.484 & $9(60 \%)$ & $35(76 \%)$ \\
\hline
\end{tabular}

right, two left) were associated with adverse outcome (table 3). Table 4 summarises the findings on echocardiography and right ventricular angiography. Significant predictors of adverse outcome were the presence of left ventricular involvement and left atrial dilatation.

Among 41 patients who underwent electrophysiological stimulation, $27(66 \%)$ had an inducible sustained monomorphic ventricular tachycardia. Two patients had ventricular tachycardia with two different morphologies and one patient had three morphologies. Twenty six patients presented with ventricular tachycardia with left bundle branch block pattern. Only one patient had an inducible ventricular tachycardia with a right bundle branch block pattern (inferior axis). Polymorphic ventricular tachycardia was induced in three patients and ventricular fibrillation was induced in four patients. Supraventricular tachyarrhythmias were commonly observed (induced or spontaneous) during follow up (atrial fibrillation 5; Wolff-Parkinson-White syndrome 4; atrial flutter 2; atrioventricular nodal re-entrant tachycardia 1). The survival analysis showed that arrhythmia inducibility in electrophysiological study was not associated with a lower rate of survival $(\log$ rank $\mathrm{p}=0.810)$.

Medical treatment was as follows: 41 patients $(67 \%)$ were taking $\beta$ blockers, 19 patients (31\%) were taking sotalol, and 16 patients $(26 \%)$ were taking amiodarone. Twenty four (39\%) patients received an implantable cardioverter-defibrillator (ICD) during follow up. The indication for ICD implantation was ventricular tachyarrhythmia with haemodynamic compromise in 22 patients and family history of sudden death in the remaining two patients. During follow up, 10 patients received appropriate shocks, whereas four patients had an inappropriate shock (atrial fibrillation in two patients, sinus tachycardia in one, and electromagnetic interference in one). Three patients with an ICD had heart transplantation during later follow up. One ICD patient died of advanced biventricular heart failure and one patient died suddenly despite delivery of several device discharges. Among the remaining patients who died suddenly, four patients were taking $\beta$ blockers (in combination with amiodarone in two patients) and one patient was taking sotalol.

\section{Multivariate analysis}

Among the variables showing a significant effect on survival in univariate survival analysis, presence of signs and symptoms of heart failure (fig 2) and left ventricular involvement on echocardiography (fig 3) were identified as independent predictors of a subsequent adverse outcome.

\section{DISCUSSION}

The clinical course of ARVD/C may vary considerably. Patients with ARVD/C die either of ventricular tachyarrhythmias or congestive heart failure. Cardiac electrical instability may be associated with ventricular arrhythmias of variable severity eventually culminating in sudden cardiac death. The disease may also progress to right or biventricular dysfunction with subsequent congestive heart failure leading to a heart transplantation or death from terminal heart failure. Previously published retrospective studies determined several predictors of subsequent mortality from sudden cardiac death, such as diffuse right ventricular dilatation, ${ }^{26-28}$ left ventricular involvement, ${ }^{26} 2930$ and previous aborted cardiac death or ventricular fibrillation. ${ }^{6829}$ Less well established factors for sudden cardiac death were family history of ARVD/C or sudden cardiac death, syncope, ${ }^{31}{ }^{32}$ ventricular tachycardia, ${ }^{6-8} 293334$ and inducible arrhythmias during programmed electrical stimulation. ${ }^{35}$ One study described the influence of congestive heart failure as a possible outcome predictor. ${ }^{10}$ The small number of patients studied and the relatively short follow up periods were limitations of previous studies.

Table 3 Twelve lead surface ECG findings in 59 patients* with ARVD/C

\begin{tabular}{|c|c|c|c|c|}
\hline & \multirow[b]{2}{*}{ No. } & \multirow{2}{*}{$\begin{array}{l}\text { Survival analysis } \\
\text { (log rank p) }\end{array}$} & \multicolumn{2}{|c|}{ Comparison at time of diagnosis } \\
\hline & & & Group A (n= 13) & Group B $(n=46)$ \\
\hline BBB & $13(22 \%)$ & $0.041+$ & $5(38 \%)$ & $8(17 \%)$ \\
\hline $\mathrm{T}$ negative beyond $\mathrm{V} 1$ & $36(62 \%)$ & 0.854 & $8(67 \%)$ & $28(61 \%)$ \\
\hline Epsilon wave & $21(36 \%)$ & 0.324 & $9(69 \%)$ & $12(26 \%)$ \\
\hline Extrasystoles & $16(27 \%)$ & 0.518 & $4(29 \%)$ & $12(26 \%)$ \\
\hline QRS V1 (ms) & $59(100 \%)$ & $0.044 \dagger$ & $123(26)$ & $101(34)$ \\
\hline QRS V6 (ms) & $59(100 \%)$ & 0.568 & $90(29)$ & $87(20)$ \\
\hline QTc (ms) & $46(78 \%)$ & 0.149 & $460(84)$ & $419(39)$ \\
\hline PR (ms) & $59(100 \%)$ & $0.008+$ & $196(63)$ & $160(41)$ \\
\hline
\end{tabular}

*No surface ECG was available for one patient with a first manifestation of SCD and no intrinsic rhythm was present in another patient.

†Significantly associated with adverse outcome.

$\mathrm{BBB}$, bundle branch block. 
Table 4 Transthoracic echocardiography and angiography findings in 59 patients * with ARVD/C

\begin{tabular}{|c|c|c|c|c|}
\hline & \multirow[b]{2}{*}{ No. } & \multirow[b]{2}{*}{$\begin{array}{l}\text { Survival analysis } \\
\text { (log rank p) }\end{array}$} & \multicolumn{2}{|c|}{$\begin{array}{l}\text { Comparison at time of } \\
\text { diagnosis }\end{array}$} \\
\hline & & & $\begin{array}{l}\text { Group A } \\
(n=13)\end{array}$ & $\begin{array}{l}\text { Group B } \\
(n=46)\end{array}$ \\
\hline $\begin{array}{l}\text { RV dilatation or reduced RV function } \\
\text { Left ventricular abnormality } \\
\text { Right atrial dilatation } \\
\text { Left atrial dilatation } \\
\text { Aneurysm }\end{array}$ & $\begin{array}{l}28(47 \%) \\
25(42 \%) \\
30(51 \%) \\
15(25 \%) \\
48(81 \%)\end{array}$ & $\begin{array}{l}0.350 \\
0.0003 \dagger \\
0.347 \\
0.041 \dagger \\
0.064\end{array}$ & $\begin{array}{l}9(69 \%) \\
11(85 \%) \\
9(69 \%) \\
7(54 \%) \\
8(62 \%)\end{array}$ & $\begin{array}{l}19(41 \%) \\
14(30 \%) \\
21(46 \%) \\
8(17 \%) \\
40(87 \%)\end{array}$ \\
\hline \multicolumn{5}{|c|}{$\begin{array}{l}\text { *No echocardiogram was available for two patients (ARVD/C diagnosed at necropsy). } \\
\text { †Significantly associated with adverse outcome. } \\
\text { Left ventricular abnormality is defined by either ejection fraction } \leqslant 50 \% \text { or the presence of dysplastic areas. } \\
\text { RV, right ventricular. }\end{array}$} \\
\hline
\end{tabular}

The present study focused on survival analysis and risk stratification of a relatively large number of patients with ARVD/C over a long term follow up period in a single tertiary care centre. Sudden and non-sudden cardiac deaths, as well as terminal heart failure requiring heart transplantation, were used as outcome measures in the context of this study. The mortality rates and the percentage of patients with left ventricular abnormality were high relative to other studies because of the long follow up in our study.

\section{Left ventricular involvement and congestive heart failure}

In the present study, left ventricular involvement and congestive heart failure were the only independent predictors of a subsequent adverse outcome. Since ARVD/C is a progressive disease, ${ }^{29}$ isolated right or global heart failure is common. While early mortality is almost always secondary to arrhythmic death, ${ }^{1-5}$ late mortality is likely due either to arrhythmias or to pump failure. ${ }^{9-11}$ Congestive heart failure occurs in the late stage of biventricular involvement ${ }^{29}$ and, in this study, it was significantly associated with adverse outcome. Therefore, congestive heart failure in association with ARVD/C may be an ominous sign to which the physician should be alerted.

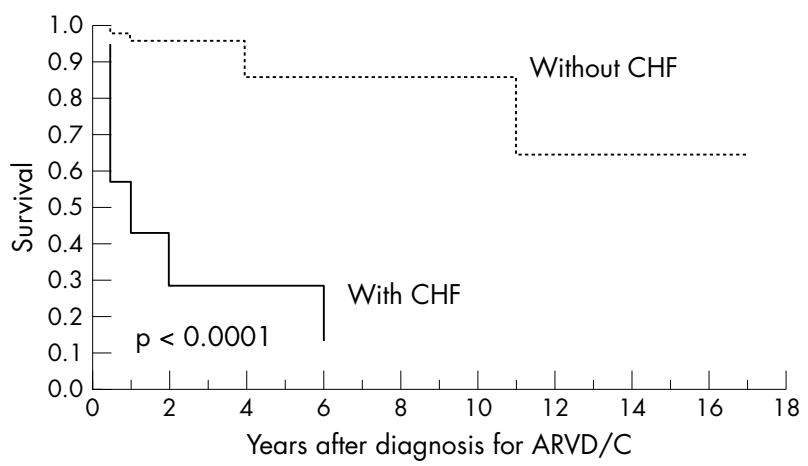

\begin{tabular}{|c|c|c|c|c|c|c|c|c|c|c|c|c|c|c|c|c|c|c|c|}
\hline FU year & 0 & 1 & 2 & 3 & 4 & 5 & 6 & 7 & 8 & 9 & 10 & 11 & 12 & 13 & 14 & 15 & 16 & 17 & 18 \\
\hline No CHF & 50 & 42 & 36 & 31 & 29 & 24 & 20 & 16 & 10 & 6 & 6 & 4 & 2 & 2 & 2 & 2 & 2 & 1 & 0 \\
\hline CHF & 7 & 4 & 3 & 2 & 1 & 1 & 1 & 0 & 0 & 0 & 0 & 0 & 0 & 0 & 0 & 0 & 0 & 0 & 0 \\
\hline
\end{tabular}

Figure 2 Kaplan-Meier survival analysis (cumulative proportion surviving) of 57 patients with ARVD/C (time from correct diagnosis to cardiac death or heart transplantation) comparing the group of patients with congestive heart failure (CHF) $(n=7)$ with the group without $\mathrm{CHF}$ $(n=50)(p<0.0001)$. The numbers of patients remaining at risk for death or heart transplantation during follow up (FU) are listed beneath the plot.
In univariate analysis, left atrial dilatation was also significantly correlated with adverse outcome in this study and was present in 15 patients. In 10 of these patients, the left ventricle was also affected, emphasising how the risk of adverse outcome in this disease is related to the extent of left heart involvement. Patients with a localised form of the disease such as aneurysms tended to have a more favourable clinical outcome probably because these findings enabled an early detection of ARVD/C.

\section{Surface ECG markers}

Conduction delay has already been investigated as a risk factor for death in ARVD/C. Dispersion of ventricular depolarisation (QRS dispersion $\geqslant 40-50 \mathrm{~ms}$ ), dispersion of repolarisation (QT dispersion $>65 \mathrm{~ms}$ ), and complete right bundle branch block were previously shown to be more common in patients with a poor outcome. ${ }^{26}{ }^{36}$ However, these studies did not have a long term follow up period. Our study showed, in univariate analysis, that prolonged PR interval, prolonged QRS in lead Vl, and presence of bundle branch block were predictors for adverse outcome. These findings provide strong evidence that abnormalities of atrioventricular and intraventricular conduction have an important role in non-invasive risk prediction of poor outcome. Prolonged QRS duration is a marker of regional inhomogeneity of

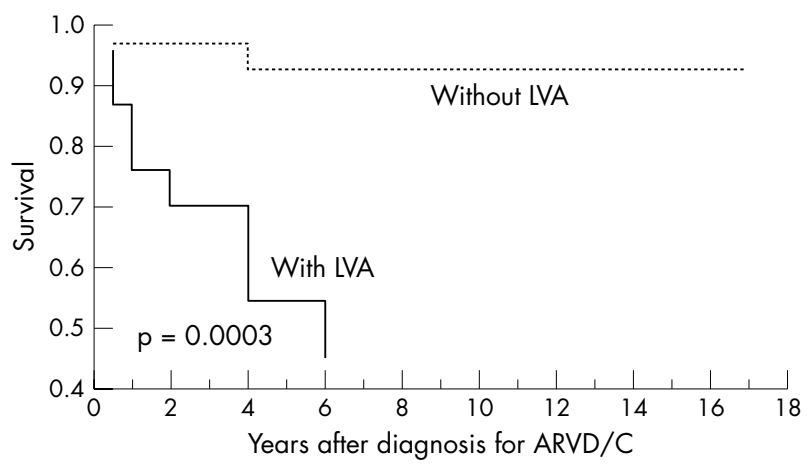

\begin{tabular}{|c|c|c|c|c|c|c|c|c|c|c|c|c|c|c|c|c|c|c|c|}
\hline FU year & 0 & 1 & 2 & 3 & 4 & 5 & 6 & 7 & 8 & 9 & 10 & 11 & 12 & 13 & 14 & 15 & 16 & 17 & 18 \\
\hline No LVA & 34 & 30 & 26 & 22 & 22 & 20 & 16 & 13 & 10 & 6 & 6 & 4 & 2 & 2 & 2 & 2 & 2 & 1 & 0 \\
\hline LVA & 23 & 16 & 13 & 11 & 9 & 6 & 6 & 4 & 1 & 1 & 1 & 1 & 0 & 0 & 0 & 0 & 0 & 0 & 0 \\
\hline
\end{tabular}

Figure 3 Kaplan-Meier survival analysis (cumulative proportion surviving) of 57 patients with ARVD/C (time from correct diagnosis to cardiac death or heart transplantation) comparing the group of patients with left ventricular abnormalities (LVA) $(n=23)$ with the group without LVA $(n=34)(p=0.0003)$. The numbers of patients remaining at risk for death or heart transplantation during follow up (FU) are listed beneath the plot. 
depolarisation and may reflect regional fibrous adipose replacement of myocardium caused by ARVD/C. Areas of slow conduction as shown during endocardial mapping studies are likely to cause the dispersion of depolarisation and provide a substrate for re-entrant arrhythmias in the right ventricle. ${ }^{83738}$

\section{Previous ventricular arrhythmias}

Both ventricular tachycardia and ventricular fibrillation have been documented in patients with ARVD/C with sudden cardiac arrest. ${ }^{629}$ The presence of sustained ventricular arrhythmia is associated with ventricular morphological abnormalities. Such patients appear to have an increased incidence of sudden cardiac death. ${ }^{35}$ However, the survival analysis in the present study did not show a significant relation between previous ventricular arrhythmias and poor outcome. The most probable explanation for the difference between this and previous studies is that some patients in this study had an ICD implanted, which may have favourably influenced the later clinical outcome of these patients. A recently published non-randomised multicentre study that investigated the impact of ICD implantation in patients with ARVD/C showed that history of cardiac arrest or ventricular tachycardia with haemodynamic compromise, along with left ventricular involvement and younger age, were independent predictors of adequate device interventions for ventricular fibrillation/flutter. ${ }^{39}$ However, whether device implantation is superior to antiarrhythmic drugs in the ARVD/C population needs to be determined in controlled randomised trials.

\section{Value of electrophysiological study}

In the present study, inducibility of ventricular tachyarrhythmias during electrophysiological studies was not associated with adverse outcome. The role of electrophysiological testing in the prediction of poor outcome in $\mathrm{ARVD} / \mathrm{C}$ is difficult to assess. This is because an abnormal electrophysiological test will invariably lead to medical or device implantation, which potentially influences outcome. The efficacy of the treatment and the stage of the disease will also influence the outcome. Therefore, the most appropriate comparison may be to assess the outcome of patients who underwent electrophysiological testing versus those who did not. However, this may create selection bias, since the indication for electrophysiological studies depends on the stage of the disease. ${ }^{35}$ Patients with inducible ventricular arrhythmias combined with extensive right or left ventricular involvement are more at risk for sudden cardiac death. ${ }^{28}$ On the other hand, the presence of multiple configurations of spontaneous or induced ventricular tachycardia in a patient may express the advanced progression of disease and, therefore, may be speculated to be an indicator for adverse outcome.

\section{Atrial tachyarrhythmias in ARVD/C}

Spontaneous atrial tachyarrhythmias, especially atrial fibrillation or flutter, are relatively common in patients with $\mathrm{ARVD} / \mathrm{C}$ and may precede ventricular tachyarrhythmias. In addition, supraventricular arrhythmias are often inducible in $\mathrm{ARVD} / \mathrm{C}^{40}$ Increased atrial myocardial vulnerability is an expression of direct involvement of the atrial myocardium or can be an indirect result of advanced ventricular myocardial disease. Our study population had a high incidence of documented supraventricular arrhythmias that could be explained by increased atrial vulnerability to the consequences of ARVD/C. These observations may lead to speculation that supraventricular arrhythmia that occurs in an otherwise healthy young patient may be the first manifestation of $\mathrm{ARVD} / \mathrm{C}$ and may warrant further investigation and follow up to rule out ARVD/C.

\section{Study limitations}

The effect of drug treatment or ICD implantation on clinical outcome could not be adequately assessed because of the retrospective design of the study and the small number of patients studied in a single centre. It is possible that ICD provided protection by effectively terminating life threatening ventricular arrhythmias in some patients. However, precise data are not available on the efficacy of ICDs compared with antiarrhythmics in patients with ARVD/C, since previous studies were not randomised. We chose not to include patients who had appropriate ICD interventions as an adverse outcome in our study, since the primary objective of this study was to identify patients who are at risk despite the best medical or device treatment in a tertiary care centre setting over the long term. However, it is possible that our study was influenced by a selection bias having included a highly selected population of patients with ARVD/C.

\section{Conclusions}

Risk factors significantly associated with adverse clinical outcome in patients with ARVD/C are congestive heart failure, the presence of left ventricular involvement on echocardiography, left atrial dilatation, prolonged PR duration, prolonged QRS in Vl, and bundle branch block. The presence of congestive heart failure and left ventricular involvement on echocardiography were determined to be independent risk predictors in this disease. Congestive heart failure usually occurs in the late stage of ARVD/C and may be an ominous sign to which the physician should be alerted.

\section{ACKNOWLEDGEMENTS}

The authors thank Randy Kardon MD PhD and Oliver Bergamin MD for their contribution to the preparation of this manuscript.

\section{Authors' affiliations}

K Lemola, C Brunckhorst, E Oechslin, R Jenni, F Duru, Division of Cardiology, Cardiovascular Centre, University Hospital of Zurich, Zurich, Switzerland

U Helfenstein, Institute of Public Health, University of Zurich, Zurich, Switzerland

\section{REFERENCES}

1 Maron BJ, Shirani J, Poliac LC, et al. Sudden death in young competitive athletes: clinical, demographic, and pathological profiles. JAMA 1996;276:199-204.

2 Shen WK, Edwards WD, Hammill SC, et al. Sudden unexpected nontraumatic death in 54 young adults: a 30-year population-based study. Am J Cardiol 1995; 76:148-52.

3 Goodin JC, Farb A, Smialek JE, et al. Right ventricular dysplasia associated with sudden death in young adults. Mod Pathol 1991;4:702-6.

4 Corrado D, Basso C, Schiavon M, et al. Screening for hypertrophic cardiomyopathy in young athletes. N Engl J Med 1998;339:364-9.

5 Tabib A, Miras A, Taniere P, et al. Undetected cardiac lesions cause unexpected sudden cardiac death during occasional sport activity: a report of 80 cases. Eur Heart J 1999;20:900-3.

6 Thiene G, Nava A, Corrado D, et al. Right ventricular cardiomyopathy and sudden death in young people. N Engl J Med 1988;318:129-33.

7 Corrado D, Thiene G, Nava A, et al. Sudden death in young competitive athletes: clinicopathologic correlations in 22 cases. Am J Med 1990;89:588-96.

8 Marcus FI, Fontaine GH, Guiraudon G, et al. Right ventricular dysplasia: a report of 24 adult cases. Circulation 1982;65:384-98.

9 Kullo IJ, Edwards WD, Seward JB. Right ventricular dysplasia: the Mayo Clinic experience. Mayo Clin Proc 1995;70:541-8.

10 Pinamonti B, Di Lenarda A, Sinagra G, et al. Long-term evolution of right ventricular dysplasia cardiomyopathy. The heart muscle disease study group. Am Heart J 1995; 129:412-5.

11 Nava A, Rossi L, Thiene G. Arrhythmogenic right ventricular cardiomyopathydysplasia. Amsterdam: Elsevier, 1997.

12 McKenna WJ, Thiene G, Nava A, et al. Diagnosis of arrhythmogenic right ventricular dysplasia/cardiomyopathy. Task force of the working group myocardial and pericardial disease of the European Society of Cardiology and of the Scientific Council on Cardiomyopathies of the International Society and Federation of Cardiology. Br Heart J 1994;71:215-8.

13 Fontaine G, Guiraudon G, Frank R, et al. Stimulation studies and epicardial mapping in VT: study of mechanisms and selection for surgery. In: 
Kulbertus HE, eds. Reentrant arrhythmias. Lancaster: MTP Publishers, 1977:334-50.

14 Fontaine G, Fontaliran F, Hebert JL, et al. Arrhythmogenic right ventricular dysplasia. Annu Rev Med 1999:50:17-35.

15 Brugada P, Brugada J. Right bundle branch block, persistent ST segment elevation and sudden cardiac death: a distinct clinical and electrocardiographic syndrome: a multicenter report. J Am Coll Cardiol 1992;20:1391-6.

16 Bazett HC. An analysis of the time-relations of electrocardiogram. Heart 1920:7:353-70.

17 Sahn DJ, DeMaria A, Kisslo J, et al. Recommendations regarding quantitation in M-mode echocardiography: results of a survey of echocardiographic measurements. Circulation 1978;58:1072-83.

18 Schiller NB, Shah PM, Crawford M, et al. Recommendations for quantitation of the left ventricle by two-dimensional echocardiography. American Society of Echocardiography committee on standards, subcommittee on quantitation of two-dimensional echocardiograms. J Am Soc Echocardiogr 1989:2:358-67.

19 Devereux RB, Alonso DR, Lutas EM, et al. Echocardiographic assessment of left ventricular hypertrophy: comparison to necropsy findings. Am J Cardiol 1986;57:450-8

20 Jenni R, Vieli A, Hess $O$, et al. Estimation of left ventricular volume from apical orthogonal 2-D echocardiograms. Eur Heart J 1981;3:217-25.

21 Daliento L, Rizzoli G, Thiene G, et al. Diagnostic accuracy of right ventriculography in arrhythmogenic right ventricular cardiomyopathy. Am J Cardiol 1990;66:741-5.

22 Daubert C, Descaves C, Foulgoc JL, et al. Critical analysis of cineangiographic criteria for diagnosis of arrhythmogenic right ventricular dysplasia. Am Heart 1988;115:448-59.

23 Candinas R, Duru F. Unusual clinical presentation of a patient with an extreme form of right ventricular dysplasia. Circulation 2001;104:848-9.

24 Kaplan EL, Meier P. Nonparametric estimation from incomplete observations. $J$ Am Stat Assoc 1958;53:457-81.

25 Cox DR. Regression methods and life tables. J R Stat Soc 1972;34:187-220.

26 Peters S, Peters H, Thierfelder L. Risk stratification of sudden cardiac death and malignant ventricular arrhythmias in right ventricular dysplasiacardiomyopathy. Int J Cardiol 1999;71:243-50.

27 Peters S. Right ventricular cardiomyopathy: diffuse dilatation, focal dysplasia or biventricular disease. Int J Cardiol 1997:62:63-7.
28 Peters S, Reil GH. Risk factors of cardiac arrest in arrhythmogenic right ventricular dysplasia. Eur Heart J 1995; 16:77-80.

29 Corrado D, Basso C, Thiene G, et al. Spectrum of clinicopathologic manifestations of arrhythmogenic right ventricular cardiomyopathy/ dysplasia: a multicenter study. J Am Coll Cardiol 1997;30:1512-20.

30 Peters S. Left ventricular impairment in arrhythmogenic right ventricular dysplasia: what we can learn from angiography. Cardiology 1995:86:473-6.

31 Blomstrom-Lundqvist C, Sabel KG, Olsson SB. A long term follow up of 15 patients with arrhythmogenic right ventricular dysplasia. Br Heart $J$ 1987;58:477-88.

32 Marcus FI, Fontaine GH, Frank R, et al. Long-term follow-up in patients with arrhythmogenic right ventricular disease. Eur Heart J 1989;10D:68-73.

33 Lemery R, Brugada P, Janssen J, et al. Nonischemic sustained ventricular tachycardia: clinical outcome in 12 patients with arrhythmogenic right ventricular dysplasia. J Am Coll Cardiol 1989;14:96-105.

34 Fontaine G, Fontaliran F, Lascault G, et al. Arrhythmogenic right ventricular dysplasia. In: Zipes DP, Jalife J, eds. Cardiac electrophysiology: from cell to bedside. Philadelphia: WB Saunders, 1994:754-68.

35 Priori SG, Aliot $E$, Blomstrom-Lundqvist $C$, et al. Task force on sudden cardiac death of the European Society of Cardiology. Eur Heart $J$ $2001 ; 22: 1374-450$

36 Turrini P, Corrado D, Basso C, et al. Dispersion of ventricular depolarizationrepolarization: a noninvasive marker for risk stratification in arrhythmogenic right ventricular cardiomyopathy. Circulation $2001 ; 103: 3075-80$.

37 Leclercq JF, Coumel P. Characteristics, prognosis and treatment of the ventricular arrhythmias of right ventricular dysplasia. Eur Heart $J$ 1989;10D:61-7.

38 Fontaine G, Guiraudon G, Frank R. Intramyocardial conduction defects in patients prone to ventricular tachycardia, parts I-III. In: Sandoe E, Julian DG, Bell JW, eds. Management of ventricular tachycardia: role of mexiletine. Amsterdam: Excerpta Medica, 1978:39-79.

39 Corrado D, Leoni L, Link MS, et al. Implantable cardioverter-defibrillator therapy for prevention of sudden death in patients with arrhythmogenic right ventricular cardiomyopathy/dysplasia. Circulation 2003;108:3084-91.

40 Brembilla-Perrot B, Jacquemin L, Houplon $\mathrm{P}$, et al. Increased atrial vulnerability in arrhythmogenic right ventricular disease. Am Heart $J$ $1998 ; 135: 748-54$.

\section{IMAGES IN CARDIOLOGY}

\section{Heterotopic heart transplantation: three dimensional image}

W

e present a case of heterotopic heart transplantation in a 47 year old man who had post-ischaemic dilated cardiomyopathy. The patient presented with an anterior myocardial infarction (MI) in 1989 and an inferior MI seven years later. Coronary radiography showed a double vessel disease and ventriculography an ejection fraction of 0.25. In March 1997 the patient underwent double coronary bypass by means of internal mammary artery (LIMA) to left anterior descending coronary artery and saphenous vein to right coronary artery. A few months following surgery the patient started to complain of debilitating dyspnoea and in December 1999 he was considered for heart transplantation. Right heart catheterisation showed systolic pulmonary pressure of $94 \mathrm{~mm} \mathrm{Hg}$ and 7.1 Wood units, and therefore he had to be considered for heterotopic heart transplantation. Finally in December 2003 he underwent heterotopic heart transplantation and during the operation the two coronary grafts implanted before were found to be functioning.

The figure represents a three dimensional reconstructionmultidetector spiral computed tomography (Sensation 16 Siemens)_of the two hearts, anteroposterior view; it is possible to identify the LIMA and the saphenous vein.

\section{A M Grande \\ C Monterosso \\ R Dore \\ $M$ Viganò}

amgrande@libero.it

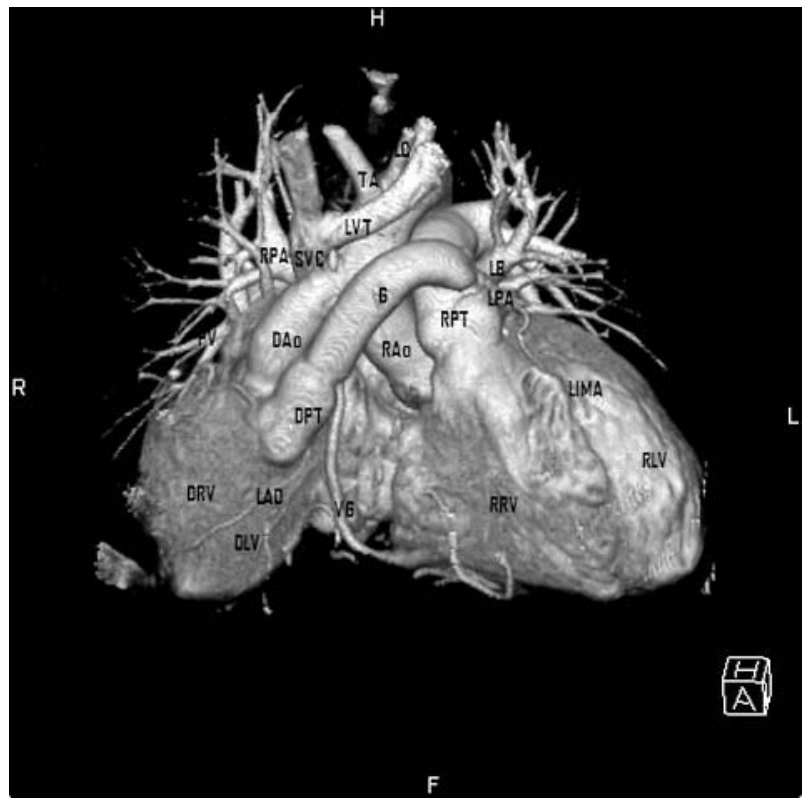

DAo, donor aorta; DLV, donor left ventricle; DRV, donor right ventricle; DPT, donor pulmonary trunk; G graft (between DPT and RPT); LB, left bronchus; LC, left carotid artery; LPA, left pulmonary artery; LVT, left venous trunk; PV, pulmonary vein; RAo, recipient aorta; RLV, recipient left ventricle; RPA, right pulmonary artery; RPT, recipient pulmonary trunk; RRV, recipient right ventricle; SVC, superior vena cava; TA, anonymous trunk; VG, saphenous vein graft. 